\title{
Lithologic boundaries from gravity and magnetic anomalies over Proterozoic Dalma volcanics
}

\author{
Pramod Kumar Yadav ${ }^{1}$, P K Adhikari ${ }^{2}$, Shalivahan Srivastava ${ }^{3}$ *, Ved P Maurya ${ }^{4}$, \\ Anurag Tripathi ${ }^{1}$, Shailendra Singh ${ }^{6}$, Roshan K Singh ${ }^{3}$ and Ashish K Bage ${ }^{5}$ \\ ${ }^{1}$ Geological survey of India, Kolkata, India. \\ ${ }^{2}$ Uranium Corporation of India Limited, Jaduguda, East Singhbhum, India. \\ ${ }^{3}$ Centre of Advanced Study, Department of Applied Geophysics, Indian Institute of Technology \\ (Indian School of Mines), Dhanbad, India. \\ ${ }^{4}$ Observatório Nacional, Rua General José Cristino, 77, Rio de Janeiro, RJ 20.921-400, Brazil. \\ ${ }^{5}$ Formerly at Centre of Advanced Study, Department of Applied Geophysics, Indian School of Mines, \\ Dhanbad, India. \\ ${ }^{6}$ Geological survey of India, Hyderabad, India. \\ *Corresponding author.e-mail: svismagp@gmail.com
}

MS received 1 September 2016; revised 29 November 2016; accepted 7 February 2017; published online 2 March 2018

Dalma volcanics (DVs) has intruded the older Singhbhum Group of Metapelites. Despite DVs being rich in mineralisation, its boundaries are not clearly demarcated. Gravity and magnetic surveys have been attempted for mapping the boundaries in DVs. These surveys were made in the northern fringe of the DVs over an area of $\sim 0.70 \mathrm{~km}^{2}$ along 13 parallel lines at $50 \mathrm{~m}$ spacing. The data was acquired at $\sim 25 \mathrm{~m}$ spacing. The surveys were taken for determination of lithological boundaries, depths and nature of causative source using Euler depth solutions and radially averaged power spectrum (RAPS). Residual anomaly maps of gravity and magnetic intensity show the same trend as that of Bouguer gravity anomaly and total magnetic intensity anomaly map indicating towards shallow sources. The magnetic map in general follows the same pattern as that of gravity anomaly maps. The map shows coincident high gravity and magnetic anomalies. These anomalies together with resistivity signatures confirm that the northern fringe of DVs hosts volcanogenic massive sulphide settings. The Euler depth solution delineated the lateral boundaries and nature of the source. It seems that the source is of spherical nature lying within a depth range of 25-40 m. The obtained lithological (vertical) units from RAPS are between Lower DVs, Upper DVs and Singhbhum Group Metapelites at depths of $\sim 15, \sim 25$ and $\sim 40 \mathrm{~m}$, respectively. The metallogeny is associated with the Upper DVs and the corresponding delineated lithological (vertical) unit is indicative of the top of the ore body. Good agreement is observed with the geological succession from the drilling data and resistivity data. The findings suggest that the northern fringe of DVs could be a preferred target for drilling.

Keywords. Lithological boundaries 1; VMS 2; gravity and magnetic 3.

\section{Introduction}

Dalma volcanics (DVs) shows a uniformly depleted mantle source identical to typical Mid Ocean Ridge
Basalt mantle (Bose 1994). Large incipient rift related thermal mid-proterozoic plume activity of 1.6 Gyr (Gupta and Basu 2000) or mafic back arc settings in an oceanic environment 
(Bose 1994) explains the evolution of DVs. Plume caused large scale crustal remobilization in Chhotanagpur Gneissic Complex (CGC) and was later uplifted to its present level (Gupta and Basu 2000). Volcanogenic massive sulphide (VMS) setting in the northern fringe of DVs can be explained by the tectonics related to such plume and belongs to bimodal felsic dominated rifted margin (Sarkar and Deb 1974; Sarkar 1984). VMS deposits are major sources of copper and zinc and, to a lesser extent, lead, silver, gold, cadmium, bismuth and minor amounts of indium (Franklin et al. 2005). Depending on the type of VMS deposit, the tonnage and metal content varies from 2.7 to $7.1 \mathrm{Mt}$.

North of DVs hosts gold deposits (Dunn 1929; Dunn and Dey 1942; Gupta 2010; Deb 2014; Geological Survey of India (http://data.gov.in/ catalog/location-gold-deposits-india-and-itssalient -features $\backslash \#$ web $\backslash$ _catalog $\backslash \_t a b s \backslash$ block $\backslash$-1)). There has been limited geophysical work in this area (Maurya et al. 2015; Adhikari et al. 2016). Maurya et al. (2015) carried out MT studies over Singhbhum Group Metapelites (SGM), Dalma volcanics (DVs) and Singhbhum Group Quartzite and Pelites (SGQP) and detected shallow conductors beneath it which coincides well with the proven gold deposit (MECL 2010). However, these conductors could not be delineated due to limited resolution of MT data. The inductively coupled plasma atomic emission spectroscopy studies indicate the presence of $\mathrm{Au}, \mathrm{Ag}, \mathrm{U}$ and $\mathrm{Cu}$ as $0.75 \mathrm{ppm}$, traces, $22 \mathrm{ppm}$ and $26 \mathrm{ppm}$, respectively (Maurya et al. 2015).

Adhikari et al. (2016) carried out detailed electrical resistivity tomography (ERT) surveys over the detected conductor by MT studies (Maurya et al. 2015) in the northern fringe of DVs. The survey was carried out to delineate the detected conductor. They delineated four major resistive zones, viz., resistivity $<1 \Omega \mathrm{m}, 1-10 \Omega \mathrm{m}, 10-100 \Omega \mathrm{m}$, and $>100 \Omega \mathrm{m}$. The metallogeny associated with resistivity $<1 \Omega \mathrm{m}$ corresponds to Upper Dalma. The top of resistivity zone $<1 \Omega \mathrm{m}$ is $\sim 25 \mathrm{~m}$.

DVs is intrusive rock and is intruded in older SGM because of mid-proterozoic rifing. The limited geophysical study in the northern fringe of DVs shows promising results in terms of mineralization. Though, DVs is rich in mineralisation, its boundaries are not clearly demarcated. Systematic gravity and magnetic survey have been attempted for mapping both the lithological (lateral) boundaries and lithological (vertical) units of SGM and DVs (figure 1). Identification of these can help in further systematic and detailed geophysical surveys for scout drilling programme. The data have been interpreted through 3D Euler depth solution and radially averaged power spectrum (RAPS). We have used 3D Euler depth solution in conjunction with amplitude of analytical signal. 3D Euler depth solution is preferred as these are boundary finder and depth estimator as well as can provide some indication of the source type (Reid et al. 1990). RAPS has been preferred as these could help in delineating the lithological units.

\section{Geology}

Arcuate shape Proterozoic Dalma volcanics (DVs) is as long as $200 \mathrm{~km}$ with a width of $3-7 \mathrm{~km}$. It lies between Singhbhum group of metapelites in the north and Singhbhum group of quartzites and pelites in the south (figure 1) and is primarily made of green schist facies of rocks of Singhbhum group and metavolcanics (Mahadevan 2002). DVs show the bimodal volcanism of the mid-basinal picrite/komatiite and basalt (Bose 1989). From the ore microscope studies, felsic volcanic indicates that the pyrrhotite is an associated sulfide (Chandan et al. 2014). DVs have been explained through various models, viz., continental rift, island arc, back-arc, and plume (Naha and Ghosh 1960; Kent 1991; Bose 1994; Das and Agrawal 2001; Roy et al. 2002). MECL (2010) obtained the geological succession (table 1) in the study area through a drill hole at Parasi (between latitude $22^{\circ} 57^{\prime} 30^{\prime \prime}$ $23^{\circ} 00^{\prime} 00^{\prime \prime} \mathrm{N}$ and longitude $85^{\circ} 40^{\prime} 30^{\prime \prime}-85^{\circ} 45^{\prime} 00^{\prime \prime} \mathrm{E}$ ) (figure 1). Northern fringe of DVs provides clear indication of metallogeny on the basis of both geological and geophysical studies (MECL 2010; Deb 2014; Jha et al. 2015; Maurya et al. 2015).

\section{Methodology}

\subsection{Analytic signal}

Nabighian (1972) expressed the complex analytic signal $A(x, y, z)$ in terms of the total field $T$ and its Hilbert transform or in terms of the horizontal $(\partial T / \partial x$ and $\partial T / \partial y)$ and vertical derivatives $(\partial T / \partial z)$ as:

$$
A(x, y, z)=\left(\frac{\partial T}{\partial x} \hat{x}+\frac{\partial T}{\partial y} \hat{y}+\frac{\partial T}{\partial z} \hat{z}\right)
$$

where $\hat{x}, \hat{y}$, and $\hat{z}$ are unit vectors in $x, y$, and $z$ directions, and $i$ is the imaginary number $\sqrt{-1}$. 


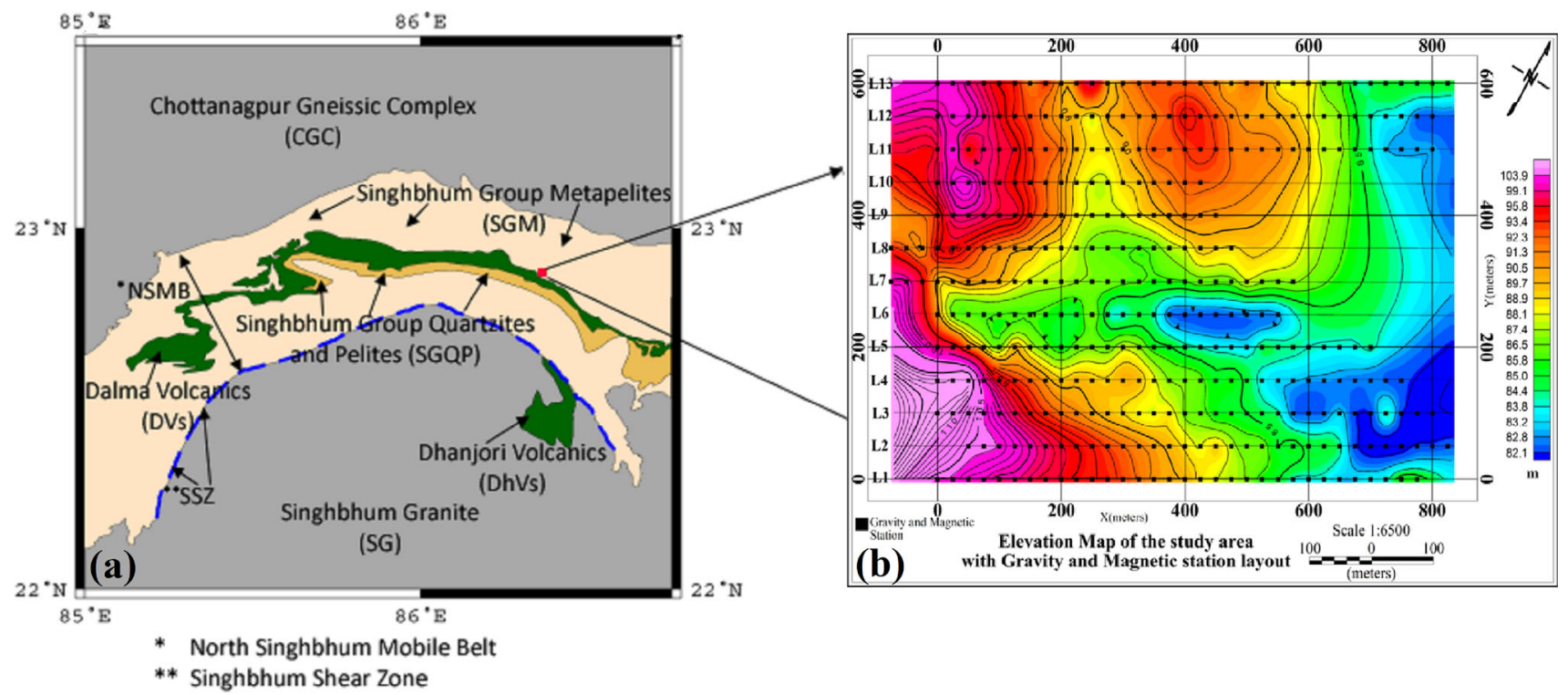

Figure 1. Plan of work: (a) Geological map of the study area (modified after Saha 1994), surveyed area is shown by red rectangle and drill hole at Parasi (with red star) and (b) inset map of elevation for coincident gravity and magnetic lines with stations as filled rectangles are the station locations.

Table 1. Geological succession of DVs in Singhbhum region, eastern India (after MECL 2010).

Soil/alluvium

Intrusives

Dalma Group

Sheared contact

Singhbhum

Supergroup
Singhbhum Group Quartzite and Pelites (SGQP)

Singhbhum Group Metapelites (SGM)
Quartz vein \& Quartz-carbonate veins with limonitic coatings, Metabasics, Ultramafics

Acid tuff, acidic volcanic breccia and Rhyolites, Tuffaceous phyllite with intercalated (schistose) quartzite/ buff grey quartzite, Carbon phyllite \pm Grey (carbonaceous) quartzite

Magnetite-quartz-biotite-sericite phyllite Schist

Magnetite-biotite-quartz-sericite schist and intercalated ferruginous quartzite
Following Roest et al. (1992), the 3D expression of amplitude of analytic signal (AAS) is as:

$$
\begin{aligned}
& |A A S(x, y, z)| \\
& =\sqrt{\left(\frac{\partial T}{\partial x}\right)^{2}+\left(\frac{\partial T}{\partial y}\right)^{2}+\left(\frac{\partial T}{\partial z}\right)^{2}} .
\end{aligned}
$$

The gradients can be obtained using fast Fourier transform in frequency domain (Blakely 1995).

\subsection{Radially averaged power spectrum}

Spector and Grant (1970) developed power spectrum tool in frequency domain to determine the depth of the anomaly source and is capable of separating information from different sources. Power spectrum $P(w)$ is the square amplitude of Fourier transform. Following Spector and Grant (1970), the mathematical expression relating $P(w)$ to depth $(h)$ is:

$$
P(w)=A \exp (-2 w h)
$$

where $A$ is the constant for randomly distributed source and $w$ is the wave number.

Taking logarithm on both sides of the above equation yields $\ln (p)=-2 w h+A$. The slope of the power spectrum-wave number plot gives the depth of the anomalous source. The slope at small wave number region gives deeper depth. Subsequent wave number region gives depth at different levels. 


\subsection{D-Euler depth solutions}

Thompson (1982) for the first time determined depth from magnetic data using Euler deconvolution. Blakely (1995) provided a comprehensive treatment of Euler deconvolution on the basis of Euler homogeneity equation. It is a powerful technique for locating anomalous source and its depth estimation for potential field data. The method is based on Euler homogeneity equation and can be expressed for potential field as follows:

$$
\begin{aligned}
(x & \left.-x_{0}\right) \frac{\partial T}{\partial x}+\left(y-y_{0}\right) \frac{\partial T}{\partial y}+\left(z-z_{0}\right) \frac{\partial T}{\partial z} \\
& =-N(B-T)
\end{aligned}
$$

where the location of causative source at $\left(x_{0}, y_{0}\right.$, $\left.z_{0}\right)$, total field $T$ is measured at $(x, y, z), B$ is the back ground field, and $N$ indicates structural index and is related to the rate of change of potential with distance.

Total field and its derivatives are determined within small convolution window to obtain solutions from Euler deconvolution. The window is scrolled across the grid to obtain source location and depth for given structural index. A least square solution gives source location with uncertainties. However, reliable solutions depend upon appropriate selection of structural index, window size and depth tolerance. The prior geological knowledge helps in selecting proper structural index.

\section{Data acquisition and processing}

Thirteen coincident gravity magnetic profiles were laid out in $\mathrm{N} 30^{\circ} \mathrm{E}-\mathrm{S} 30^{\circ} \mathrm{W}$ perpendicular to the regional geological strike. The profiles are of $\sim 1 \mathrm{~km}$ with profile and station spacing of $\sim 50$ and $\sim 25 \mathrm{~m}$, respectively. Gravity measurements were made using CG-5 with an accuracy of $0.001 \mathrm{mGal}$. Magnetic measurements were made using, Proton Precession Magnetometer with an accuracy of $1 \mathrm{nT}$. At each station, both for gravity and magnetic measurements, five readings were taken for better accuracy. The average of these five readings were used for data reduction and interpretation. Verma et al. (1984) analysed gravity field over Singhbhum and adjoining areas. They used a density value of $2.67 \mathrm{~g} / \mathrm{cm}^{3}$ for the reduction of gravity data. They have mentioned that the "...major error in gravity value is due to elevation which is generally within $\pm 5 \mathrm{ft}$ and amounts to an error of $0.3 \mathrm{mGal}$ in Bouguer anomaly...".
Thus, it was felt to acquire elevation data of higher accuracy. Geodetic surveying employing total station instruments for measuring the elevation of each gravity station was obtained at an accuracy of less than $10 \mathrm{~cm}$. The acquired gravity data over land for geophysical exploration should be reduced for drift, elevation, Bouguer, latitude and terrain before preparing the anomaly map(s) (Hinze et al. 2005). The acquired gravity data was reduced by applying drift correction and combined elevation correction including both free air and Bouguer correction. The latitude correction for gravity and normal correction for magnetic data were not applied as the study area is $\sim 0.70 \mathrm{~km}^{2}$ only. Also, the terrain correction for gravity data was ignored as the elevation of the study area varied from $\sim 78$ to $\sim 115 \mathrm{~m}$. Diurnal correction was only applied to the acquired magnetic data. The base station for gravity and magnetic measurement was fixed outside the survey area devoid of noise. The base reading for the gravity and magnetic surveys was taken at an interval of $2-3 \mathrm{hr}$ for better monitoring of drift and diurnal variations, respectively. The combined elevation correction was applied by using $(0.3086-2 \pi G \rho) h$, where gravitational constant $(G)$ is $6.673 \times 10^{-11} \mathrm{~m}^{3} / \mathrm{kg} / \mathrm{s}^{2}, \rho$ is the density of the Bouguer slab and $h$ is the geoid height. Following Verma et al. (1984), we have used the average crustal density of $2.67 \mathrm{~g} / \mathrm{cm}^{3}$ for anomaly calculation. These reduced data were used for the preparation of Bouguer gravity anomaly map and total magnetic intensity anomaly map.

The separation of regional and residual anomaly of the Bouguer gravity anomaly and magnetic field anomaly is necessary for the quantitative interpretation. The regional field can be obtained by using upward continuation (Nettleton 1954; Fuller 1967; Keating and Pinet 2011). Jacobsen (1987) assumed that the field is due to an ensemble of mutually uncorrelated thin sources. The field from a slab located $\mathrm{z} 1$ and $\mathrm{z} 2$ is basically the difference between the field upward continued to 2z1 and 2z2 (Jacobsen 1987). Keating and Pinet (2011) have shown that, in general, the effect of bodies is less than the half of upward continuation height. ERT lines coincident with gravity and magnetic lines in the area show that the top of the ore body is $\sim 25 \mathrm{~m}$ and extends to a maximum depth of $\sim 50 \mathrm{~m}$ (Adhikari et al. 2016). Following Keating and Pinet (2011) and keeping the ERT results in consideration, we have chosen the upward continuation at $150 \mathrm{~m}$ as 
(a)

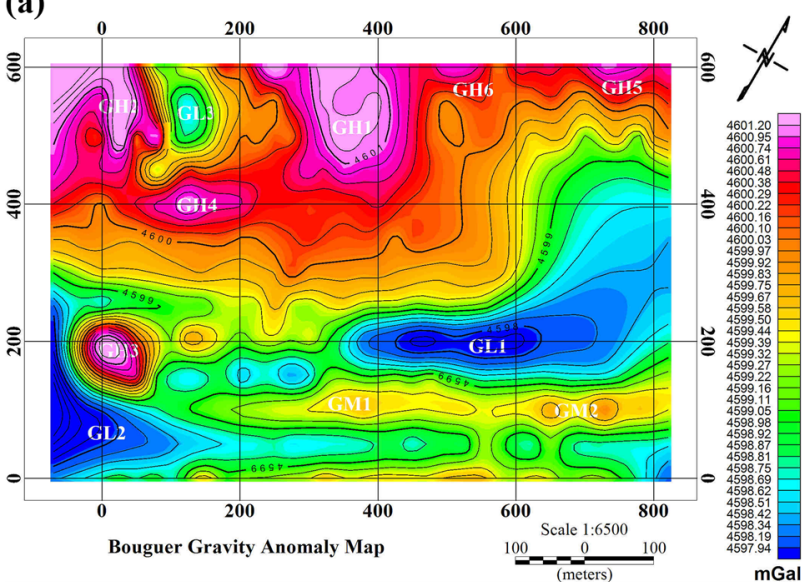

(c)

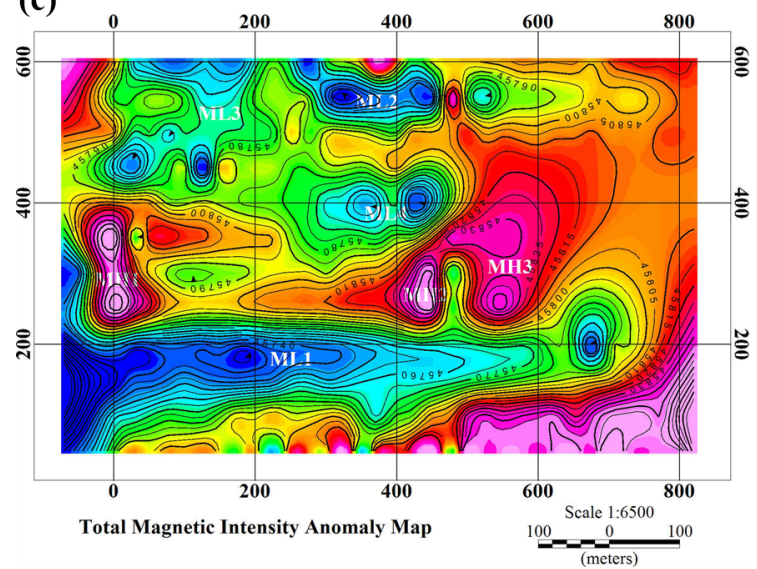

(b)

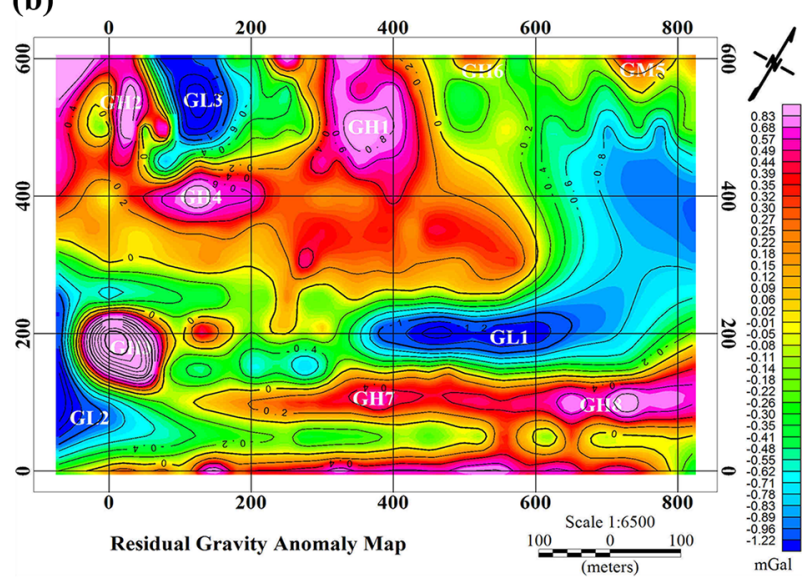

(d)

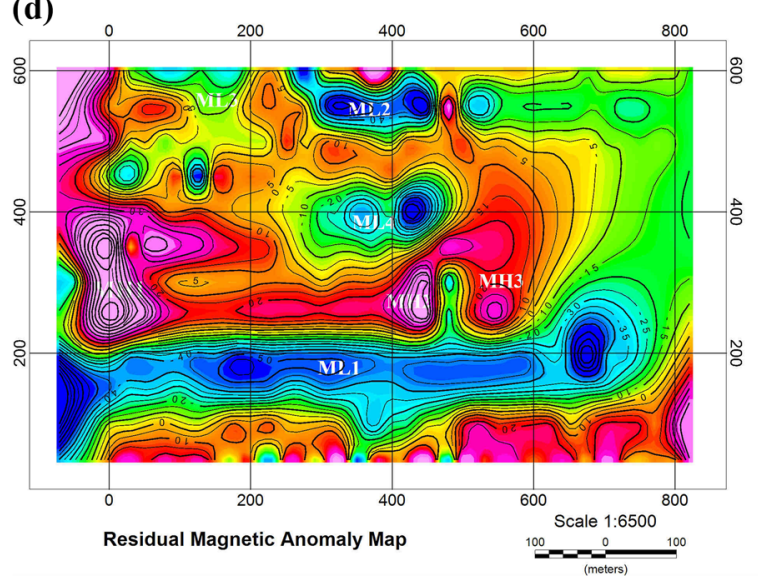

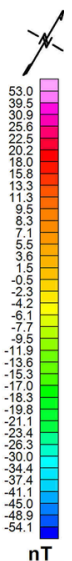

Figure 2. (a) Bouguer gravity anomaly map, (b) residual gravity anomaly map, (c) total magnetic intensity map, and (d) residual magnetic anomaly map.

regional anomaly both for gravity and magnetic studies. The upward continuation at $150 \mathrm{~m}$ is subtracted from Bouguer gravity anomaly and total magnetic intensity anomaly to get the residual gravity anomaly and residual magnetic anomaly, respectively. Gravity and magnetic analytic signals were generated by using the gravity and magnetic residuals, respectively.

\section{Results and discussion}

The Bouguer gravity anomaly map with a scale of 1:6500 and $0.2 \mathrm{mGal}$ contour interval shows the variation in anomaly of $\sim 3.0 \mathrm{mGal}$ (figure $2 \mathrm{a}$ ). The map is characterized by the conspicuous presence of several gravity highs GH1, GH2, GH3, GH4, GH5 and GH6 and lows GL1 and GL2 and GL3. Moderate gravity highs GM1 and GM2 show linear trend extending beyond the profile of measurement. Isolated closure GL1 is surrounded by GH1, GH2 and GH4, whereas GL2 extends beyond the map. The gravity highs GH5 and GH6 are observed at the boundary of the map.

The residual gravity anomaly map (figure $2 \mathrm{~b}$ ) is obtained by separating $150 \mathrm{~m}$ upward continuation, as a regional feature, from the Bouguer gravity anomaly map (figure $2 \mathrm{a}$ ). A variation of $\sim 2.0 \mathrm{mGal}$ is seen in the study area. The four prominent positive gravity high closures GH1, GH2, GH3 and GH4 along with linear prominent highs GH7 and GH8 are observed (figure 2b). These linear prominent highs extend beyond the map. The highs GH7 and GH8 were observed as moderate highs GM1 and GM2 (figure 2b) in Bouguer anomaly map (figure 2a). The highs GH5 and GH6 are observed at the edge of the map. Interestingly, the residual gravity anomaly map (figure $2 \mathrm{~b}$ ) shows similar trend as that of Bouguer gravity anomaly map (figure 2a) indicating that the anomalies are due to the shallower sources.

Total magnetic intensity anomaly map with a scale of 1:6500 was prepared using the contour intervals of $5 \mathrm{nT}$ (figure 2c). The map shows the 

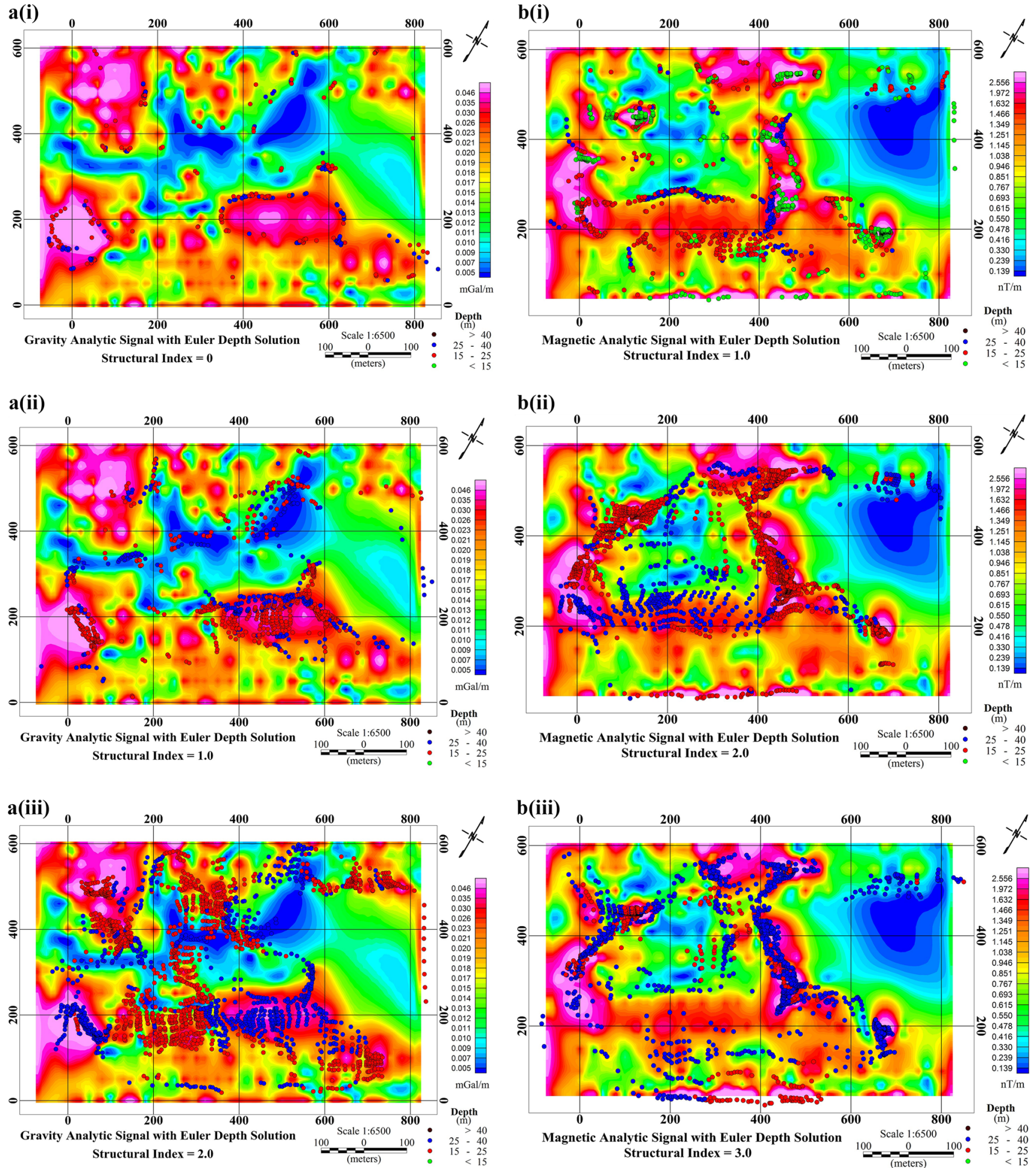

Figure 3. (a) Euler depth solutions for different structural indices overlapped over amplitude of analytical signal of gravity data. (i) 0, (ii) 1.0, and (iii) 2.0. Source depth is indicated by filled circle diameter which is proportional to the depth. (b) Euler depth solutions for different structural indices overlapped over amplitude of analytical signal of magnetic data. (i) 1.0, (ii) 2.0, and (iii) 3.0. Source depth is indicated by filled circles of different colours.

variation in anomaly of $\sim 130 \mathrm{nT}$. Figure $2(\mathrm{c})$ is characterized by the conspicuous presence of three magnetic high closures MH1, MH2 and MH3 and four magnetic lows ML1, ML2, ML3 and ML4.
ML1 shows a linear trend, whereas ML2, ML3 and ML4 are closures.

The residual magnetic anomaly map (figure $2 \mathrm{~d}$ ) is obtained by separating $150 \mathrm{~m}$ upward 

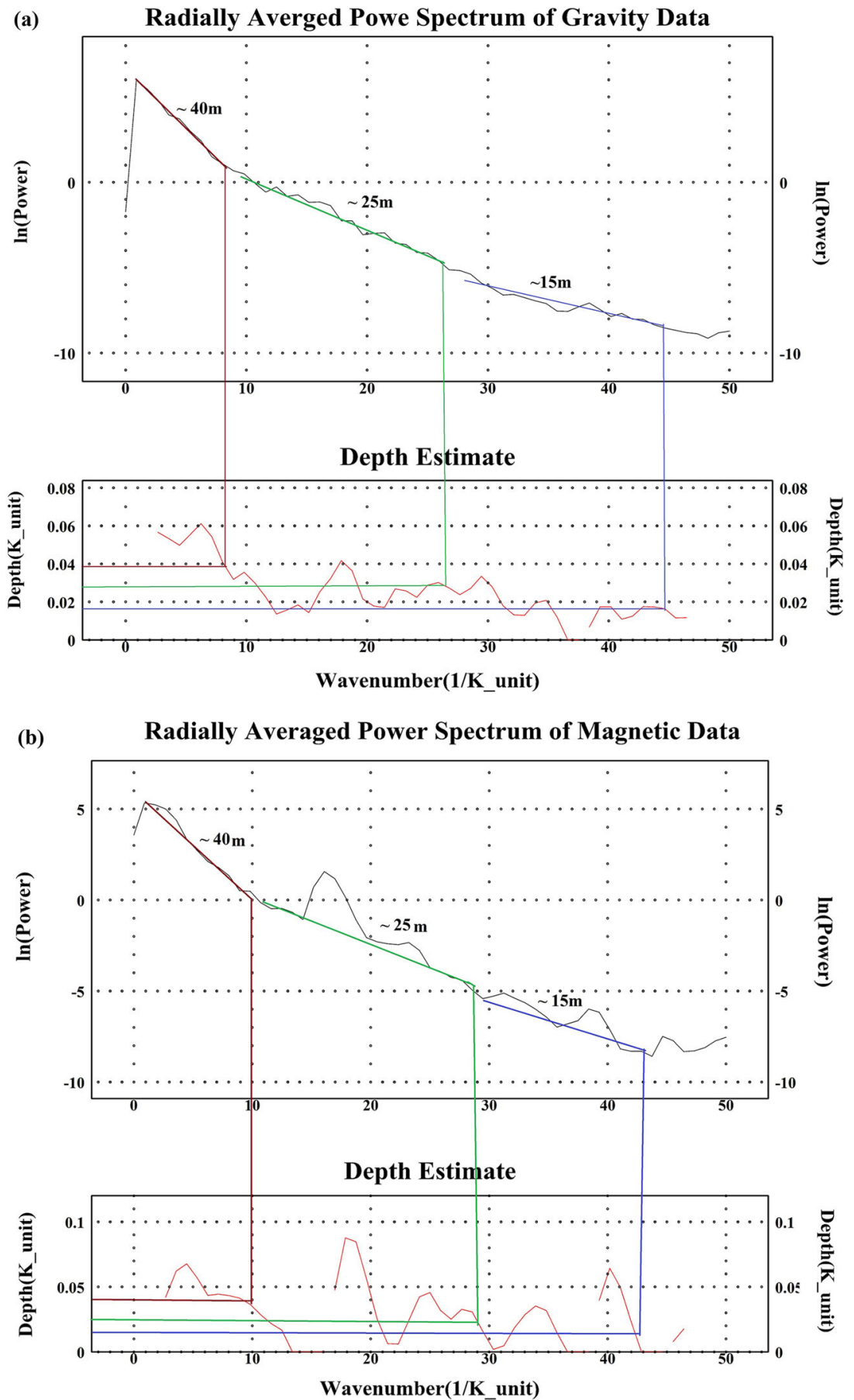

Figure 4. Radially averaged power spectrum: (a) gravity data and (b) magnetic data.

continuation, as a regional feature, from the total magnetic intensity map (figure 2c) that shows a variation of $\sim 110 \mathrm{nT}$. Three distinct prominent positive magnetic high closures $\mathrm{MH} 1, \mathrm{MH} 2$ and MH3 and four magnetic lows ML1, ML2, ML3 and ML4 are observed. ML2, ML3 and ML4 are closures whereas ML1 shows a linear trend. The residual anomaly map (figure $2 \mathrm{~d}$ ) shows similar trend as that of total magnetic intensity anomaly map (figure 2c) indicative of shallower sources. The magnetic maps (figure 2c, d), in general, follow the same pattern as that of gravity anomaly maps (figure 2a, b).

Euler depth solutions shown as circles with different colours at their plan positions (figure 3) are calculated using the analytic signal map of gravity and magnetic data. Structural index (SI) for gravity data of $0.0,1.0$ and 2.0 corresponds to 
thin sheet edge/sill/dyke, pipe/vertical pole and spherical sources, respectively (Reid and Thurston 2014). For similar bodies, the SI for magnetic data would be one order higher than that of the gravity data. To map the lateral boundary, the solution for gravity data has been derived with $\mathrm{SI}=0.0$ and the nature of the causative source with SI as 1.0 and 2.0 (figure 3a(i), (ii) and (iii)). The Euler depth solutions for $\mathrm{SI}=0$ gives the depth of the lateral boundaries mainly in the range of $15-25 \mathrm{~m}$ (figure 3ai). For SI $=1.0$, the Euler depth solutions are concentrated in the central part of map within the depth range of 15-25 $\mathrm{m}$ (red colour) with some solutions in depth range 25-40 m (blue colour). The tightest clustering seems to be for $\mathrm{SI}=2.0$ indicating that the nature of causative source is spherical. The Euler depth solution over magnetic analytic signal for the SI values 1.0, 2.0, and 3.0 is shown in figure $(3 \mathrm{~b})$. The Euler depth solution for $\mathrm{SI}=1.0$ demarcates the lateral boundary with depth in all ranges (figure $3 \mathrm{bi}$ ). For SI $=2.0$, the Euler depth solution gives a good clustering in the depth range 15-25 m (red colour) with some solutions in depth range 25$40 \mathrm{~m}$ (blue colour) (figure 3bii). SI $=3.0$ gives the tightest clustering of Euler depth solutions that may be due to the spherical type body in depth range 25-40 $\mathrm{m}$ (blue colour) with some solutions in depth range 15-25 m (red colour) (figure 3biii). However, poor clustering/lack of Euler solution in the Euler depth solutions is also observed. Reid et al. (1990) attributed the lack of Euler solutions due to interference between several neighbouring anomalies or due to irregular shape bodies.

The vertical boundary between SGM and DVs boundaries have been obtained using RAPS (Spector and Grant 1970). RAPS maps for gravity and magnetic data are shown in figure 4(a and b). It is observed that both the gravity and magnetic maps show identical lithological units. The three lithological units at depths $\sim 40, \sim 25$, and $\sim 15 \mathrm{~m}$, respectively correspond to weathered intrusive/SGM, upper DVs and lower DVs and corroborate well with the major geological successions (table 1) obtained from drilling data at Parasi $\left(22^{\circ} 57^{\prime} \mathrm{N} ; 85^{\circ} 40^{\prime} \mathrm{E}\right)$ (figure 1 ) in the same geological domain as that of the study area; a proven gold prospective deposit (MECL 2010). The obtained results are in agreement with those of Adhikari et al. (2016). They at a depth of $\sim 25 \mathrm{~m}$ obtained resistivity $<1 \Omega \mathrm{m}$ and attributed it to metallogeny coinciding to upper DVs.

\section{Conclusion}

We discuss the results of gravity and magnetic survey in the northern fringe of DVs which is expected to host volcanogenic massive sulphide (VMS) setting. The study area mainly covers overlying lower and upper members of Proterozoic DVs and underlying SGM stratigraphically. The measurements were made in an area of $\sim 0.70 \mathrm{~km}^{2}$ along 13 lines with a line and data spacing of $\sim 50$ and $\sim 25 \mathrm{~m}$, respectively. The interpretation of the data was intended for finding the lithological boundaries and lithological units. This has been attempted through 3D Euler depth solution in conjunction with amplitude of analytical signal and radially averaged power spectrum. Coincident high gravity and magnetic anomalies are observed in the study area. This along with earlier resistivity signature confirms that the northern fringe of DVs host VMS settings. The Euler depth solution delineates lithological boundaries with fairly good precision. The obtained nature of the causative source for both gravity and magnetic results from Euler depth solution seems to be spherical and lies within a range of 25-40 m. The RAPS shows three lithogical units which are coincident with lower DVs, upper DVs and SGM. The obtained results are in good agreement with the geological succession. The boundary between lower DVs and upper DVs (corresponding to metallogeny) is at a depth of $\sim 25 \mathrm{~m}$. The study indicates that the northern fringe of DVs should be a preferred target for drilling.

\section{Acknowledgements}

The authors thank the University Grants Commission and Department of Science and Technology as well as the Indian School of Mines for financial support. Authors are also thankful to the anonymous reviewers.

\section{References}

Adhikari P K, Yadav P K, Srivastava Shalivahan, Maurya V P, Singh Shailendra, Tripathi Anurag, Singh R K and Bage A K 2016 Near-surface high resolution imaging of a metallogenic zone in the northern fringe of Dalma volcanics in eastern India using electrical resistivity tomography; Expl. Geoph., https://doi.org/10.1071/ EG15078.

Bose M K 1989 Precambrian mafic magmatism in the Singhbhum Craton, eastern India; J. Geol. Soc. India 73 $13-35$. 
Bose M K 1994 Sedimentation pattern and tectonic evolution of the Proterozoic Singhbhum basin in the eastern Indian shield; Tectonophys. 231 325-346.

Blakely R J 1995 Potential theory in gravity and magnetic applications; Cambridge University Press, Cambridge.

Chandan K K, Jha V, Roy S, Khatun M, Sahoo P R and Singh S 2014 Ore microscopic study of the gold mineralization within Chandil Formation, North Singhbhum Mobile Belt, eastern India; IJEE 6 213-222.

Das L K and Agrawal B N P 2001 The evolution of the Singhbhum Craton: A geophysical perspective; Indian Minerals 55 143-170.

Deb M 2014 Precambrian geodynamics and metallogeny of the Indian shield; Ore Geol. Rev. 57 1-28.

Dunn J A 1929 The geology of north Singhbhum including parts of Ranchi and Manbhum districts; Geol. Surv. India Memoir 54 1-128.

Dunn J A and Dey A K 1942 Geology and petrology of Eastern Singhbhum and surrounding areas; Geol. Surv. India Memoir, 69p.

Franklin J M, Gibson H L, Jonasson I R and Galley A G 2005 Volcanogenic massive sulfide deposits, In: Economic Geology 100th Anniversary Volume (eds) Hedenquist J W, Thompson J F H, Goldfarb R J and Richards J P, The Economic Geology Publishing Company, pp. 523560 .

Fuller B D 1967 Two-dimensional frequency analysis and design of grid operators; Mining Geophysics II 658708.

Gupta A 2010 Gold mineralization in the eastern segment of Indian Precambrian shield: A review, In: Gold Metallogeny India and Beyond (eds) Deb M and Goldfarb R J, Narosa Publishing House Pvt. Ltd., New Delhi, pp. 256280 .

Gupta A and Basu A 2000 North Singhbhum Proterozoic mobile belt, eastern India - a review; Geol. Surv. India Spec. Publ. 55 195-226, http://data.gov.in/catalog/ location-gold-deposits-india-and-its-salientfeacher\#web_ catalog_tabsblock1.

Hinze W J, Aiken C, Brozena J, Coakley B, Dater D, Flanagan G, Forsberg R, Hildenbrand T, Keller G R, Kellogg J N, Kucks R, Li X, Mainville A, Morin R, Pilkington M, Plouff D, Ravat D, Roman D, Urrutia-Fucugauchi J, Veronneau M, Webring M and Winester D 2005 New standards for reducing gravity data: The North American gravity database; Geophysics 70 J25-J32.

Jacobsen B H 1987 A case for upward continuation as a standard separation filter for potential field maps; Geophysics 52 1138-1148.

Jha V, Singh S and Venkatesh A S 2015 Invisible gold occurrence within the quartz reef pyrite of Babaikundi area, North Singhbhum fold-and-thrust belt, Eastern Indian Shield: Evidence from petrographic, SEM and EPMA studies; Ore Geol. Rev. 65(1) 426-432.
Keating P and Pinet N 2011 Use of non-linear filtering for the regional-residual separation of potential field data; J. Appl. Geophys. 73 315-322.

Kent R W 1991 Lithospheric uplift in eastern Gondwana: Evidence for a long lived mantle plume system; Geology 19 19-23.

Mahadevan T M 2002 Geology of Bihar and Jharkhand; Geol. Soc. India, Bangalore, 569p.

Maurya V P, Shalivahan S, Bhattacharya B B and Das L K 2015 Preliminary magnetotelluric results across Dalma volcanics, eastern India: Inferences on metallogeny; $J$. Appl. Geophys. 115 171-182.

MECL 2010 Geological report on detailed exploration for gold ore in Parasi (Central Block) Gold Deposit - PhaseI \& Phase-II, North of Sonapet Anticline, Dist: Ranchi, Jharkhand

Nabighian M N 1972 The analytic signal of two-dimensional magnetic bodies with polygonal cross-section: Its properties and use for automated anomaly interpretation; Geophysics 37 507-517.

Naha K and Ghosh S K 1960 Archean palaeogeography of E. and N. Singhbhum; Geol. Mag. 97 436-439.

Nettleton L L 1954 Regionals residuals and structures; Geophysics 19 1-22.

Reid A B, Allsop J M, Granser H, Millett A J and Somerton I W 1990 Magnetic interpretation in three dimensions using Euler deconvolution; Geophysics 55 80-91.

Reid A B and Thurston J B 2014 The structural index in gravity and magnetic interpretation: Errors, uses, and abuses; Geophysics 79 J61-J66.

Roest W R, Verhoef J and Pilkington M 1992 Magnetic interpretation using 3-D analytic signal; Geophysics $\mathbf{5 7}$ 116-125.

Roy A, Sarkar A, Jeyakumar S, Aggarwal S K and Ebihara M 2002 Mid-Proterozoic plume-related thermal event in eastern Indian craton: Evidence from trace elements, REE geochemistry and $\mathrm{Sr}-\mathrm{Nd}$ isotope systematics of basicultrabasic intrusives from Dalma volcanic belt; Gondwana Res. 5 133-146.

Saha A K 1994 Crustal evolution of Singhbhum-North Orissa, eastern India; Geol. Soc. India Memoir 27 341p.

Sarkar S C 1984 Geology and ore mineralisation along the Singhbhum copper uranium belt; Jadavpur University, Calcutta, Eastern India, 263p.

Sarkar S C and Deb M 1974 Metamorphism of the sulfides of the Singhbhum copper belt, India - the evidence from the ore fabric; Econ. Geol. 68 1283-1293.

Spector A and Grant F S 1970 Statistical models for interpreting aeromagnetic data; Geophysics 35 293-302.

Thompson D T 1982 EULDPH - A new technique for making computer assisted depth estimates from magnetic data; Geophysics 47 31-37.

Verma R K, Sharma A U S and Mukhopadhyay M 1984 Gravity field over Singhbhum, its relationship to geology and tectonic history; Tectonophys. 106 87-107. 